\title{
The Status and Social Functions of female social organization Taking Jinan as a Case
}

\author{
Lixia Liang \\ College of Political Science and Law, University of Jinan, Jinan, Shandong, China \\ LLIxia76@163.com
}

Keywords: female, social organization, social governance.

\begin{abstract}
Female social organizations are women-oriented, and target women, children, and families as the main clients, which fully depend on the characteristics and advantages of women, and have a wide range of influence, cohesion, and appeal in the urban and rural women. Female social organizations are not only an important part of social organizations, but also a significant force of participating in social governance, where presents an unique practical features. Through conducting a survey on female social organizations in Jinan, the research mainly analyzes the characteristics, development status, and social functions of female social organizations.
\end{abstract}

\section{Introduction}

At present, China is in an important historical period of building a well-off society in an all-round way and realizing the great rejuvenation of the Chinese nation. With the rapid advancement of economic marketization reforms, the diversification trend of social development has become increasingly obvious, and the era of modernization of social governance is urgently required. The modernization of social governance is inseparable from the integration of social resources, social organizations that spring up in the process of economic marketization reform and social pluralism development are important social resources for the modernization of social governance, which are indispensable for constructing a new governance system.

Female social organizations are women-oriented, and target women, children, families as the main clients. which fully depend on the characteristics and advantages of women, and have a wide range of influence, cohesion, and appeal in the urban and rural women. female social organizations are not only an important part of social organizations, but also a significant force of participating in social governance, where presents an unique practical features.

\section{Characteristics of female social organizations}

As an important part of social organizations, female social organizations not only have the common characteristics of general social organizations, but also have their own unique characteristics, especially in the process of integrating social resources and promoting the modernization of social governance, which are gradually highlighted.

\subsection{Affinity}

Female social organizations fully embody the affinity of women for caring others and nature. The internal operation of the organization is based on emotional bonds, which are used to link and organize members, and integrate organization resources. In particular, some social organizations regard knowledgeable women as the main body, whose activities are characterized by affinity and flexibility. They also use emotional soft power to integrate social resources and provide social services in various fields.

\subsection{Devotion}

Female social organizations fully demonstrate the quality of women's willingness to dedicate. No matter whether it is the person in charge of the organization or the participants of the organization, they all do their best with no payments, take care of others, and serve the society, dedicating to the 
organization's guiding ideology and specific activities highlights the characteristics and advantages of female organizations. These female social organizations don't have strong interest pursuits, highlighting the selfless service consciousness and dedication, and also guiding the value orientation of society, which are conducive to the formation of a good social morality and become a positive energy for social governance.

\subsection{Inclusive}

Women have a wide range of interests and contact multiple fields. Female social organizations also cover and participate in various aspects such as economy, politics, culture, society, and ecology. In terms of service concepts, service areas, content of activities, membership, and many other aspects, female social organizations pay more attention to inclusiveness, assimilation, communication, coordination, and compromise.

\subsection{Relevance}

Women shoulder rather many family roles such as wife, mother, daughter, and daughter-in-law than corresponding social roles at the meantime, furthermore, an excellent female social organization will have an important influence on families, communities and even society.

\section{The development of female social organizations}

After nearly four decades of development, female social organizations in Jinan have exerted their unique advantages, actively pooled and integrated resources, which have been become an indispensable and critical social force in the process of advancing the modernization of social governance. The development status and trend of female social organizations in Jinan mainly exhibit the following four characteristics.

\subsection{Rapid development}

The development of female social organizations in Jinan has gone through three development stages. From the Third Plenary Session of the Eleventh Central Committee to the 1990s, the Reform and Opening promoted the women's personality independence and economic independence, a large number of women went out of their homes to society, aiming to pursuit their own values, and women-centered social organizations were in the embryonic stage, from the 1990s to the end of the 20th century, with the pace of marketization reforms accelerating, the society tend to be a diversified development, and female development and demands have also become increasingly diversified, prompting female social organizations to enter a period of vigorous development; since the party's 18th National Congress, accompanying the Party Central Committee centered on the general secretary Jinping $\mathrm{Xi}$ to put forward the thinking and tasks of modernizing the country's governance system and governance capabilities, female social organizations in Jinan have entered a period of rapid development and consolidation stage. More than 3,000 female social organizations have emerged from the city, whose development basis and scale of the organization have gradually been consolidating and expanding, and it has gradually improved in aspects of organizational structure and activity mechanism.

\subsection{Various types of organizations}

\subsubsection{The type of production and management}

It is mainly composed of rural women who combine their own characteristics to co-produce or operate mutual assistance organizations for products. For example, the Baiyun Lake Wuyuan "Fruit Women's Cooperative" in Zhangqiu of Jinan was established in 2011, a self-organizing business organization created by women, which drives local women to start their own businesses, purchases and supplies required production materials to cooperative members, buys and sells the planted fruits, and conduct the transportation, storage, processing and packaging services required by members, introduces and cultivates the new technology and new breeds and so on, thus promoting the economic income of local women. 


\subsubsection{The type of cultural and fitness class}

It largely aims to enrich urban and rural women's spiritual and cultural life and enhance their personal qualities, including dance teams, folk orchestras, calligraphy and painting agencies, and opera clubs that are active in various urban and rural communities in Jinan. For example, the "Colorful Dance Team" of the Weidong Xindu Community in Jinan, whose members are mostly retired women over the age of 60, learning to dance on time every Tuesday and Thursday and becoming an important force in advancing the construction of a "quality community".

\subsubsection{The type of community service}

There are mainly female social organizations that provide various services for community residents. For example, the "Freaky Gang", female parent-child club within the community of Lishan Prefecture of Lixia district in Jinan, which is a female social organization to serve women and adolescents with the ultimate goal of improving the quality of community family life services. The organization provide eight types of community services for district women and children such as family financial management, beauty body shaping, temperament improvement, and children training.

\subsubsection{The type of charity}

This kind of of female social organizations mainly engages in social welfare, social assistance, social security and social affairs. For example, the "Bing Mama Love Group" established by Yazhen Qi, a famous caring person in Jinan and engaged in charity for 20 years, has become a typical representative to pass positive energy and love, forming a social brand; moreover, there are many other charitable female social organizations such as "Women's Heroes to Helping the Disabled", "The Community Women's Team to Protect Green" and so on.

\subsubsection{The type of maintaining rights and interests}

This sort of female social organizations is mostly dedicated to maintain and protect women's rights and interests, for example, the "Hui Li Female Lawyers Volunteer Group" established in 2009 is the first professional women's rights protection organization in Shandong, which consists of experienced female lawyers, marriage and family counselors and women psychological counselors, they have been providing legal support services for women lasting many years.

\subsection{Obvious regional characteristics}

Affected by factors such as the level of economic development in different districts and counties and the characteristics of demographic structure, women social organizations appear distinct characteristics and qualities in different regions, the degree and the level of organization development are also distinct. The districts and counties with higher levels of economic development have more mature organization development, richer organization types, larger organization scales, and more significant social benefits.

\subsection{Independent and frequent activities}

The female social organizations in Jinan are active in all kinds of the public aspects, showing their unique characteristics, excellent abilities, required needs, and full of vitality. The outstanding performance is that a group of female elites embody the power of various social strata and interest groups, holding rich and colorful social activities to realize their own values, and paying attention to social affairs to promote social development as the value orientation of activities. Whether it is a square dance organization with the middle-aged and older woman as the main body, or a freaky gang centered on young and fashionable mothers, or a rights protection group or studio largely consisting of professional woman, they all present the quality of vigor and vitality and meet multiple level of female demands, deeply welcomed by all social circles.

\section{Social functions of female social organizations}

\subsection{Making up for promoting women's self-liberation and self-development}

The large-scale and diverse types of female social organizations meet the diversified needs of 
female groups in the new period, enrich their lives, and promote their self-liberation and self-development, meanwhile improve the quality of life of women groups. For example, the"Wuyuan Fruit Women Cooperative" in Zhangqiu provides a platform for female employment and re-employment, promoting the economic independence and gender equality of rural women. The "Happiness Class" offers training to women to deal with family relationships and social relations, promoting themselves self-growing and self-development.

\subsection{Helping to facilitate family happiness and social harmony}

The special activity contents supplied by female social organizations are often closely related to women, children and families, which focus on activities that enhance the humanistic quality of women and children and promote shaping family culture. The series of activities organized by female social organizations such as "Parents Sharon", "Confucius School" and "Smart Bean Volunteer Mother Group" stress on fostering harmonious family relationships between husband and wife ,parents and children, and developing green and healthy family lifestyles, building a mutually beneficial and harmonious neighborhood relationship, while not only promoting the quality of women and children but also facilitating family happiness and social harmony.

\subsection{Benefiting to resolve social conflicts and relieve social pressure}

Nowadays, China is in the period of social transformation, social anxiety has become a relatively common social phenomenon, a large number of social contradictions have affected the stability and development of society. Female social organizations take advantage of their own unique merits to actively mediate and coordinate family and neighborhood disputes, and grass-roots social conflicts, effectively exerting the role of "lubricant" and "buffer." Different female social organizations vocalize and solve women's issues and conflicts on behalf of different female groups. "We have enhanced communication and solidarity among different social classes and groups, and have played their own functions and roles in promoting social harmony and stability."

\subsection{Accelerating the development of public services and promoting social governance}

Female social organizations integrate the power of female groups at all levels and gather the positive energy of female groups in serving the society, some female social organizations such as charities, organizations of maintaining rights and interests, and agencies of providing community service have begun to undertake social public services and become important carrier in providing public services, which have played a role in promoting social and economic development, prospering social undertakings, and participating in public administration. However, in this process, it is also necessary to strengthen the guidance of female social organizations, great guidance will promote its sustainability as a powerful positive energy for social development; in turn, poor guidance may also cause certain negative effects.

\section{Acknowledgments}

This article is one of the phased achievements of the National Social Science Foundation's youth project "the Study on Stress and Social Support for Family Elderly Caregivers to the Disabled" (13CRK012).

\section{References}

[1] Women's Federation of Pudong New Area, Shanghai. Where does the vitality of women's social organizations come from?[J]. Chinese Women's Movement, 2016(5):27-29.

[2] http://politics.people.com.cn/n/2015/0708/c70731-27268797.html

[3] Hong Qiang, Fan Duan. The Role,Difficulties and Development Countermeasures of Women's Social Organizations[N]. Chinese Women's Daily, 2016-1-19-B02. 